\title{
Aluminium Phthalocyanine Nanoparticles Application for Fluorescent Diagnostics and Photodynamic Therapy in Dentistry
}

\section{Zolotareva (Kuznetsova) Ju.0. ${ }^{1}$, Farrakhova D.S. 1,2, and Loschenov V.B. ${ }^{1,2}$}

${ }^{1}$ National Research Nuclear University MEPhl (Moscow Engineering Physics Institute), Kashirskoe shosse 31, Moscow, 115409, Russia

${ }^{2}$ A.M. Prokhorov General Physics Institute, Russian Academy of Science, Moscow, Russian Federation

\section{Abstract}

Early diagnosis of tooth-enamel microcracks is of great importance in modern dentistry for caries prevention. It is known that the accumulation of the bacteria in the enamel microcracks can be reason of caries. A promising substance for early diagnostics of the accumulation of pathogenic microflora on the tooth enamel surface is aluminum phthalocyanine (AIPC).

Corresponding Author: Zolotareva (Kuznetsova) Ju.0. JOKuznetsova@mail.ru

Received: 17 January 2018

Accepted: 25 March 2018

Published: 17 April 2018

Publishing services provided by Knowledge

(c) Zolotareva (Kuznetsova) Ju.O. et al. This article is distributed under the terms of the

which permits unrestricted use and redistribution provided that the original author and source are credited.

Selection and Peer-review under the responsibility of the PhysBioSymp17 Conference Committee.
It could be observed that AIPc does not fluoresce in the nanoparticles form but in the monomeric molecular form it does. This allows identification of local pathological microflora accumulation within microcracks of the tooth enamel because AIPC nanoparticles (nAIPc) can be activated by pathological microflora.

This paper describes the nAIPc application for fluorescent diagnostics (FD) of the enamel surface in vitro. To reduce the time from the beginning of interaction of nAIPc with the microflora to the appearance of nAIPc fluorescence, Protelan MST-35 surfactant was used as an additional activator.

For FD in dentistry a model compound with nAIPc, Protelan MST-35 and with the complementary components was prepared. The following components were used as complementary: the methylparaben, carbopol, carboxymethyl cellulose, titanium dioxide, sodium phosphate, sodium saccharin and sorbitol, which are commonly used in toothpastes.

Human teeth were used for the investigation of the interaction between nAIPc colloid and the model compound with nAIPc for the detection of microcracks and the areas of accumulation of pathogenic microflora on the enamel surface.

Statistical processing of the experimental results showed the effectiveness of the surfactant usage for the additional activation of nAIPc and a reduction in the FD time. The application of nAIPc as a marker will make it possible to detect microcracks of the enamel tooth surface at the earliest stages and the areas of the pathogenic microflora accumulation, which can lead to the development of a caries.

Keywords: fluorescent diagnostics, nanoparticles, aluminum phthalocyanine, Protelan MST-35, surfactants, enamel microcracks, tooth enamel. 


\section{Introduction}

Applications of photodynamic therapy (PDT) and fluorescent diagnostics (FD) in dentistry become popular because these methods are noninvasive, nondestructive, inexpensive and enable real-time monitoring [1]-[4]. Likewise, in the PDT and FD methods the photosensitizers (PS) are used more often in the form of nanoemulsions and nanosolution (so-called nanophotosensitizers) due to the fact that photophysical substance properties are changed at the transition to nanoscale [5]. One of these is sulphonated aluminum phthalocyanine (commercial name Photosens, FGUP GNC"NIOPIK", Moscow, Russia) [4], [6]-[13].

In contrast to the molecular AIPc form the nAIPc does not have intrinsic fluorescence in a colloidal solution in free form. Fluorescence occurs when AIPc molecules become detached from an AIPc particle (e.g. on contact with bacteria, macrophages, etc.) [7], [9], [14]-[17]. Therefore, hydrophobic AlPc nanoparticles can be a "marker" for the detection of the hidden inflammation and places of pathogenic microflora accumulation during FD application.

It has been shown recently that some oral bacteria, including Prevotella intermedia [18], Porphyromonas gingivalis [18], [19], [20] Streptococcus mutans [21], [18], [22], Streptococcus sanguis [19], Fusobacterium nucleatum [20], Actinobacillus actinomycetemcomitons [19], [21] are susceptible to and can be killed by red light after sensitization with AIPc. Therefore, the usage of nAIPc for antimicrobial PDT and FD will allow us not only to detect the places of pathogenic microflora accumulation on the surface and in microcracks of tooth enamel but also to kill it.

Biologically compatible surfactant Protelan MST-35 was used as an additional activator of AIPc to shorten the duration and increase the effectiveness of the enamel FD. A fraction of AIPc molecules begin to separate from the AIPc particle surface, but do not separate completely, when Protelan MST-35 is added to the AIPc colloid. Without detaching from the particle surface these molecules can interact with the microenvironment and exhibit fluorescent and photodynamic properties of the molecular form of AIPC.

\section{Material and methods}

\subsection{Preparation of the AIPc colloid}

An aqueous colloidal suspension of nAlPc at a concentration of $10 \mathrm{mg} / \mathrm{l}$ was obtained from a large-dispersed water-insoluble AIPc powder (FGUP GNC"NIOPIK", Moscow, 
Russia). The powder of AlPc in distilled water was subjected to ultrasonic dispersion for 30 minutes with Bandelin SONOPLUS HD2070 (Germany). The hydrodynamic radius of the obtained nanoparticles, measured with the Photocor light-scattering spectrometer complex (Russia), was $\sim 152 \pm 60 \mathrm{~nm}$ (70\% of the total volume). It is significant that the colloidal suspension of the nanoparticles does not fluoresce when it is irradiated at 633 $\mathrm{nm}$. To study the interaction of nAIPc with the surface microflora of enamel a colloid of nAlPc at a concentration of $10 \mathrm{mg} / \mathrm{l}$ was used.

\subsection{Preparation of the model compound}

For performing of the tooth enamel FD, the model compound containing nAIPc (10 $\mathrm{mg} / \mathrm{l})$, Protelan MST-35 (1\% by volume) and the complementary components was prepared. The following components were used as complementary: the methylparaben, carbopol, carboxymethyl cellulose, titanium dioxide, sodium phosphate, sodium saccharin and sorbitol, which are commonly used in toothpastes. Protelan MST-35 is the surfactant, which was obtained from 100\% natural materials and it does not harm the human body and the environment.

Before preparing the model compound, the structure and concentration of the components were optimized. Sample of the model compound were examined immediately after preparation and after being in a special thermostat ( $42{ }^{\circ} \mathrm{C}, 1$ month), which is equivalent to being at room temperature for 12 months. Special mixing of components to produce the model compound (with nAIPc and Protelan MST-35) and thermostating was carried out by Cosmeceutical Incubator Ltd (Russia)

To investigate the spectroscopic properties of nAIPc, the additional samples were used: the basis of the model compound without the nAIPc and surfactant and the model compound with nAIPc. Additional samples of the model compound were prepared to test the hypothesis that the surfactant can activate the surface molecules of a nanoparticle like a solvent. The difference between a nanoparticles solvent and a surfactant is that the solvent transfers the surface molecules to the completely free state, while the surfactant makes them more mobile and capable of rapid interaction with the microflora without detaching them from the nanoparticle surface. Protelan MST-35 is the surfactant, which was obtained from 100\% natural materials and it does not harm the human body and the environment.

Human teeth were used for the investigation of the interaction between nAIPc colloid and the model compound with nAIPc for the detection of microcracks and the areas of accumulation of pathogenic microflora on the enamel surface. Human teeth 
were extracted for different reasons: $53 \%(n=22)$ - chronic periodontitis, $28 \%$ ( $n=$ 11 ) - third molars ("wisdom teeth"), 9.5\% ( $n=4)$ - orthodontic reasons, 9.5\% ( $n=4)$ - other reasons ( 41 samples in total). After extraction, all samples were placed into tubes with a $0.9 \%$ sodium chloride solution.

During the experiments the nAIPc colloid or the model compound was applied to the surface of the tooth enamel and in 3 minutes was removed by water.

\subsection{Experimental setup}

For the fluorescence measurements the fiber-optic spectrometer LESA-01 (BIOSPEC Ltd, Moscow, Russia) was used (Fig. 1). A helium-neon laser with a wavelength of 633 $\mathrm{nm}$ and an output power of 2-4 $\mathrm{mW}$ at the fiber probe was used as an irradiation source for fluorescence excitation. A fiber-optic probe with one irradiation and six receiving fibers (each of $200 \mu \mathrm{m}$ in diameter) was attached to the spectrometer. Detailed information about the experimental setup can be found in the paper [23].

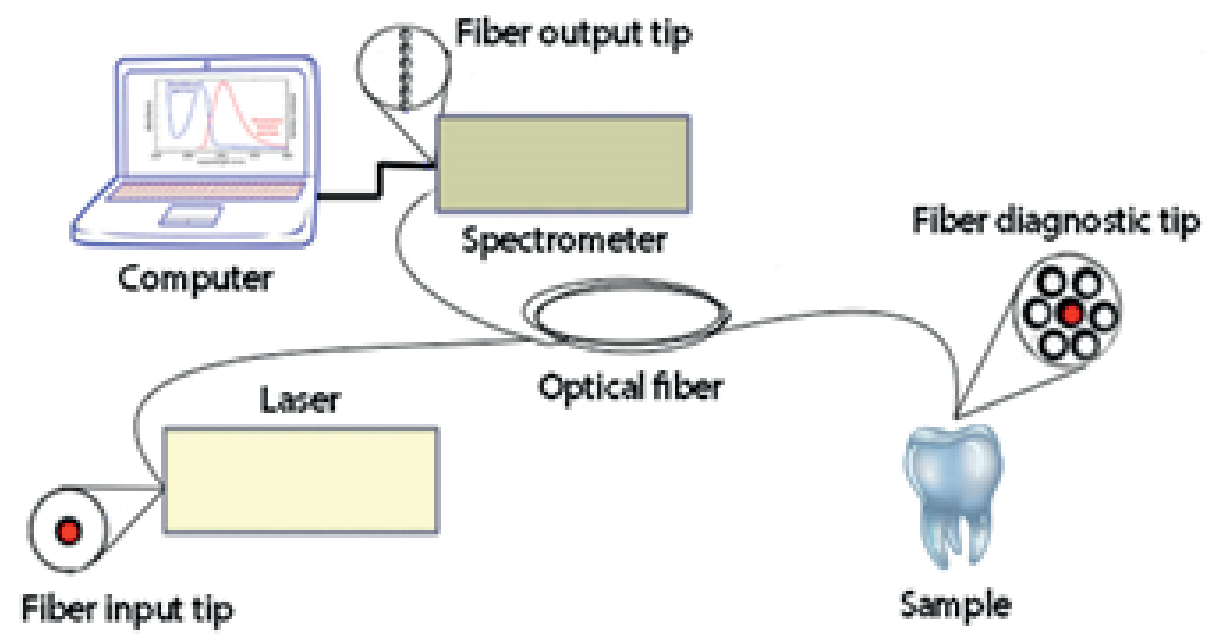

Figure 1: Experimental setup.

A video fluorescent system was used to visually control the increase of the nAIPc fluorescence. The system consists of a laser radiation source $(635 \mathrm{~nm})$, an optical filter with a transmission range of 650-1500 nm and a sensitive black-and-white camera. The original fluorescent images are presented, weren't subjected to additional processing. 


\subsection{The processing of the experimental data}

For each sample from different regions on the tooth surface the fluorescence spectra before and after the nAIPc colloid/model compound application were obtained using LESA-01.

The autofluorescence coefficient $\mathrm{K}_{a f l}$ of enamel was calculated as the ratio of the areas under the enamel autofluorescence spectrum to the area under the laser peak ("Uno Momento" software). Then the values of the enamel autofluorescence from all researched regions on the enamel surface were averaged across a single sample. Similar calculations were performed to compute the fluorescence coefficient $\mathrm{k}_{f l}$ after the application of the nAIPc colloid/model compound of a single sample. The normalization to the laser peak makes it possible to quantitatively compare the results of measurements that were obtained from different samples and to exclude the dependence of the results of spectrometry on the power of the laser radiation.

To estimate the differences in fluorescence from the enamel surface before and after applying the experimental compositions with nAlPc the coefficient of diagnostic contrast $\mathrm{k}_{D C}$ was calculated for each sample:

$$
k_{D C}=\frac{k_{f l}}{k_{a f l}}
$$

Statistical processing of the experimental results was carried out using the computer program "SPSS statistics V23.0". To compare two groups of teeth (at application nAIPC colloid or model compound with nAIPc) Student's t-test was used.

\section{Results and discussion}

\subsection{The results of interaction of the AIPc colloid and the model compound with the surface microflora of the tooth enamel in vitro}

For FD of the tooth enamel surface the model compounds containing nAIPc, surfactant and the complementary components were prepared. The fluorescence spectra of various samples of the model compounds are shown in Fig. 2.

On the graph, the peak at $633 \mathrm{~nm}$ corresponds to the backscattered laser radiation from the surface of the sample, which was used to normalize the fluorescence spectra $(670 \mathrm{~nm})$ and to quantitavely estimate the concentration of the fluorescent components. As can be seen from the graphs the basis of the model compound (without 


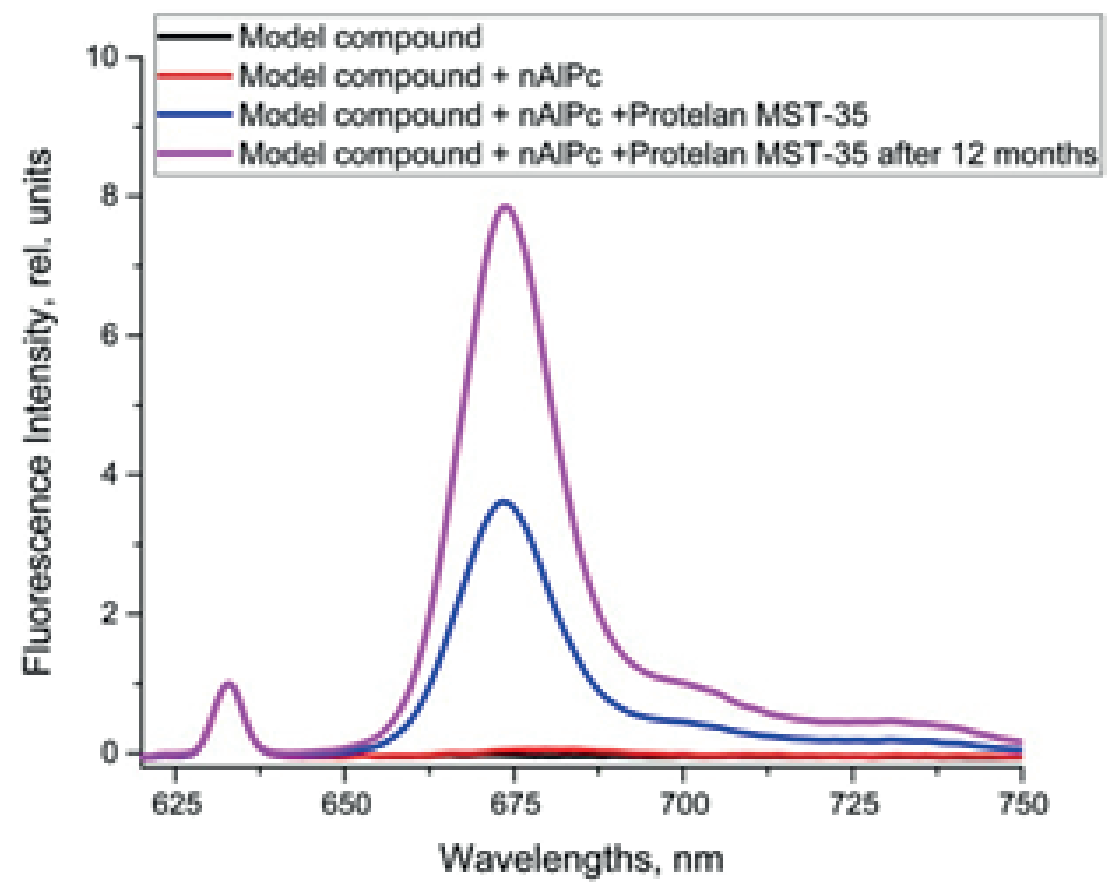

Figure 2: The fluorescence spectra of various samples of the model compounds: the basis of the model compound (without the nAIPc and surfactant), the model compound with nAIPc and the model compound (with nAIPc and Protelan MST-35), obtained immediately after preparation and after simulated 12 months.

the nAIPc and surfactant) and the model compound with nAIPc are an almost entirely 'black body' from the spectroscopic point of view.

It should also be noted that the spectroscopic properties of the model compound measured immediately after preparation and after 12 months have changed. The fluorescence intensity of nanoparticles in the model mixture increased 2-fold after 12 months. Thus, the model mix can be used for diagnostics after 12 months.

It was also found that in the model compound in the activated state there is 1$2 \%$ of AlPc molecules from their total number, which corresponds to a certain part of the surface molecules that are in the active state. The hydrogen index $(\mathrm{pH})$ of the model compound was 6.27. Enterobacteriaceae, Pseudomonas aeruginosa, Staphylococcus aureus, mold fungi and yeast were absent in the model compound. Thus, the model compound has microbiological purity, homogeneous and thick consistency, which makes it suitable for using in the clinical application.

Then, the interaction of the model compound (with nAIPc and Protelan MST-35) with the surface microflora of the tooth enamel was investigated. For each sample, the diagnostic contrast coefficient was calculated, as described in the materials and 
methods. In Figure 3, the enamel autofluorescence spectrum before and the nAIPc fluorescence after application of the model compound are presented.

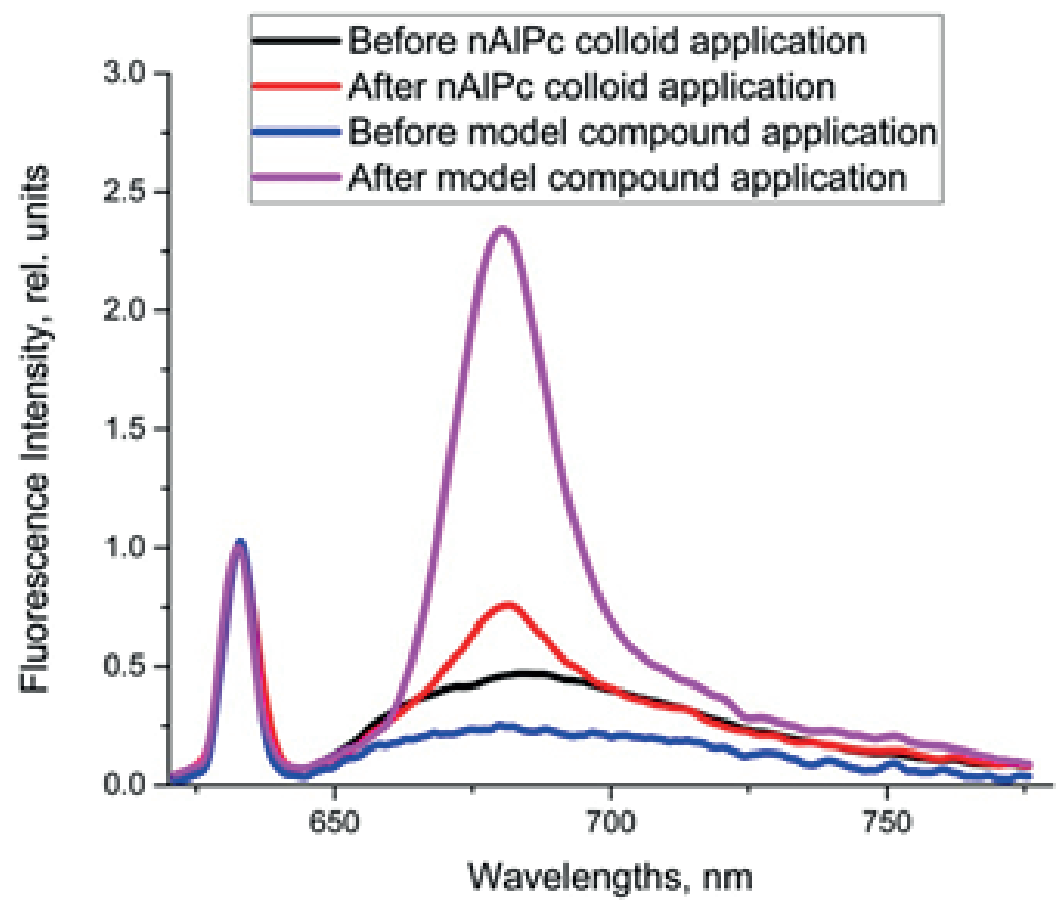

Figure 3: The example of fluorescence increases of nAIPc after application of the model compound with surfactant compared to the application of the nAIPc colloid on the enamel surface. Measurements were made after 3 minutes after application.

Figure 4 shows the video - fluorescent images of the tooth enamel surface before and in 3 minutes after the model compound application.

Statistical analysis by Student's t-test has shown that the average $\mathrm{k}_{D C}$ of the model compound (with nAIPc and Protelan MST-35) is significantly greater than the average $\mathrm{k}_{D C}$ of the nAIPC colloid ( $p<0.05$ ). Thus, the usage of Protelan MST-35 for additional activation of nAIPc is justified.

\section{Conclusions}

The results of experimental studies demonstrated the promise of using Protelan MST35 as an additional activator of nAlPc to reduce the time and increase the effectiveness of FD. Also, in vitro studies have shown that the application of the model compound with nAIPc and Protelan MST-35 allows to perform the FD of tooth enamel surfaces in 3 minutes after application. It is also possible to use a model compound for detecting the plaque, dental calculus and hidden places of pathogenic microflora accumulation in the oral area. This fact speaks about promising prospects of using the developed 


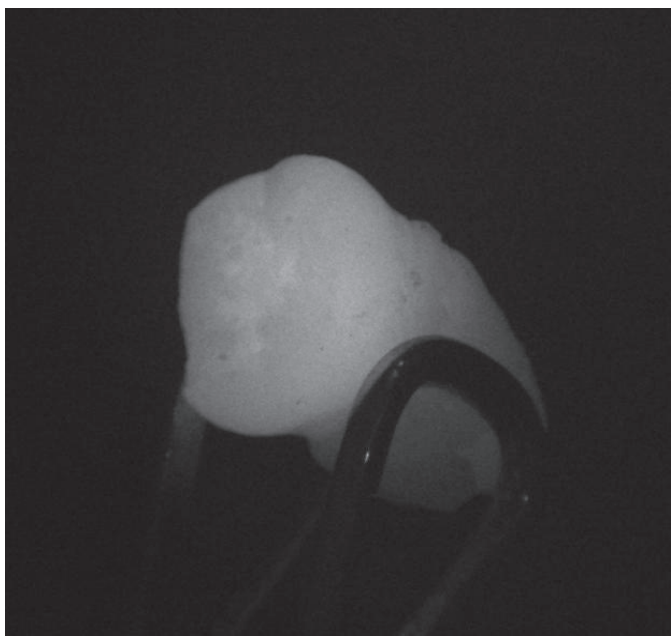

(A )

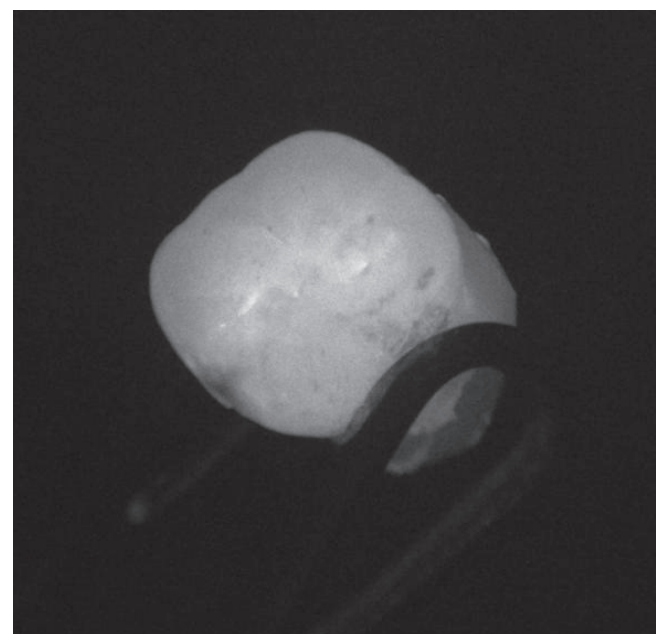

( B )

Figure 4: Figure 4 shows the video - fluorescent images of the tooth enamel surface before $(A)$ and in 3 minutes after (B) the model compound application.

model compound in dentistry as a convenient tool for FD in real time and at a low cost of the procedure.

In the future joint using of nAIPc and surfactants can allow to increase the sensitivity and effectiveness FD and PDT methods in dentistry for detection not only change of enamel surface but also inflammation processes in periodontal tissue.

\section{Acknowledgment}

The authors are grateful to Dr. E. N. Kupriyanova from the State Autonomous Healthcare Institution of Moscow "Dental Clinic N. 11 of the Moscow City Health Department" which provided the human biological samples and has taken part in the discussion of the work.

\section{References}

[1] E. T. Carrera, H. B. Dias, S. C. T. Corbi, and R. A. C. Marcantonio, "The application of antimicrobial photodynamic therapy (aPDT) in dentistry: A critical review," Laser Phys., vol. 26, no. 12, 2016.

[2] H. Gursoy, C. Ozcakir-Tomruk, J. Tanalp, and S. Yilmaz, "Photodynamic therapy in dentistry: A literature review," Clin. Oral Investig., vol. 17, no. 4, pp. 1113-1125, 2013.

[3] F. F. Sperandio and and M. R. H. Caetano P. Sabino, Daniela Vecchio, Maria GarciaDiaz, Liyi Huang, Ying-Ying Huang, "Chapter 7. Antimicrobial photodynamic therapy 
in dentistry," in Lasers in Dentistry: Guide for Clinical Practice, John Wiley \& Sons, pp. 40-47, 2015.

[4] J. P. F. Longo, S. C. Leal, A. R. Simioni, M. De Fátima Menezes Almeida-Santos, A. C. Tedesco, and R. B. Azevedo, "Photodynamic therapy disinfection of carious tissue mediated by aluminum-chloride-phthalocyanine entrapped in cationic liposomes: An in vitro and clinical study," Lasers Med. Sci., vol. 27, no. 3, pp. 575-584, 2012.

[5] V. Uskoković and L. E. Bertassoni, "Nanotechnology in Dental Sciences: Moving towards a Finer Way of Doing Dentistry," Materials (Basel)., vol. 3, no. 3, pp. 16741691, 2010.

[6] L. A. Muehlmann, B. C. Ma, J. P. F. Longo, M. de F. M. Almeida Santos, and R. B. Azevedo, "Aluminum-phthalocyanine chloride associated to poly(methyl vinyl ether-co-maleic anhydride) nanoparticles as a new third-generation photosensitizer for anticancer photodynamic therapy.," Int. J. Nanomedicine, vol. 9, no. 1, pp. 1199-213, 2014.

[7] S. Y. Vasilchenko et al., "Application of aluminum phthalocyanine nanoparticles for fluorescent diagnostics in dentistry and skin autotransplantology.," J. Biophotonics, vol. 3, no. 5-6, pp. 336-46, 2010.

[8] J. O. Kuznetsova, D. S. Farrakhova, and M. G. Yassin, "Aluminum phthalocyanine nanoparticles as a contrast agent for the detection of tooth enamel microcracks," in Photon Lasers Med, vol. 5, no. 4, pp. 267-322, 2016.

[9] R. Steiner, J. Breymayer, A. Rück, V. Loschenov, and A. Ryabova, "Crystalline organic nanoparticles for diagnosis and PDT," vol. 9308, p. 93080, 2015.

[10] C. Lim et al., "Nanophotosensitizers toward advanced photodynamic therapy of Cancer," CANCER Lett., Vol. 334, no.2, pp. 176-187 2012.

[11] C. S. De Paula, A. C. Tedesco, F. L. Primo, J. M. C. Vilela, M. S. Andrade, and V. C. F. Mosqueira, "Chloroaluminium phthalocyanine polymeric nanoparticles as photosensitisers: Photophysical and physicochemical characterisation, release and phototoxicity in vitro," Eur. J. Pharm. Sci., vol. 49, no. 3, 2013.

[12] L. A. Muehlmann et al., "Aluminium-phthalocyanine chloride nanoemulsions for anticancer photodynamic therapy: Development and in vitro activity against monolayers and spheroids of human mammary adenocarcinoma MCF-7 cells.," J. Nanobiotechnology, vol. 13, no. 36, 2015.

[13] M. de Moraes et al., "Effects of photodynamic therapy mediated by nanoemulsion containing chloro-aluminum phthalocyanine: A histologic and immunohistochemical study in human gingiva," Photodiagnosis Photodyn. Ther., vol. 12, no. 4, pp. 592-597, 2015. 
[14] J. Breymayer, A. Ruck, A. V. Ryabova, V. B. Loschenov, and R. W. Steiner, "Fluorescence investigation of the detachment of aluminum phthalocyanine molecules from aluminum phthalocyanine nanoparticles in monocytes/macrophages and skin cells and their localization in monocytes/macrophages," Photodiagnosis Photodyn. Ther., vol. 11, no. 3, pp. 380-390, 2014.

[15] D. S. Farrakhova, J. O. Kuznetsova, and V. B. Loschenov, "The study of laser induced fluorescence of tooth hard tissues with aluminum phthalocyanine nanoparticles," J. Phys. Conf. Ser., vol. 737, p. 12048, 2016.

[16] J. O. Kuznetsova and V. I. Makarov, "Application of nanophotosensitizers (aluminum phthalocyanine nanoparticles) for early diagnosis and prevention of inflammatory diseases," J. Phys. Conf. Ser., vol. 737, no. 1, pp. 1-3, 2016.

[17] S. Y. Vasilchenko, A. I. Volkova, S. B. Korovin, V. B. Loschenov, M. L. Sinyaeva, and $\mathrm{E}$. Al., "Investigation of aluminium phthalocyanine nanoparticles fluorescence properties in tooth enamel microdamages," Photodyn. Ther., vol. 5, no. 2, pp. 77-80, 2006.

[18] J. A. Lacey and D. Phillips, "Fluorescence lifetime measurements of disulfonated aluminium phthalocyanine in the presence of microbial cells.," Photochem. Photobiol. Sci., vol. 1, no. 6, pp. 378-383, 2002.

[19] J. Dobson and M. Wilson, "Sensitization of oral bacteria in biofilms to killing by light from a low-power laser," Arch. Oral Biol., vol. 37, no. 11, pp. 883-887, 1992.

[20] R. Yin and M. R. Hamblin, "Antimicrobial Photosensitizers: Drug Discovery Under the Spotlight," Curr. Med. Chem., vol. 22, no. 18, pp. 2159-2185, 2015.

[21] C. C. Tonon et al., "Comparative effects of photodynamic therapy mediated by curcumin on standard and clinical isolate of Streptococcus mutans," J. Contemp. Dent. Pract., vol. 16, no. 1, pp. 1-6, 2015.

[22] J. a. Lacey and D. Phillips, "The photobleaching of disulfonated aluminium phthalocyanine in microbial systems," Photochem. Photobiol. Sci., vol. 1, no. 2, pp. 120-125, 2002.

[23] V. Loschenov, V. Konov, and A. Prokhorov, "Photodynamic therapy and fluorescence diagnostics," Laser Phys., vol. 10, no. 6, pp. 1188-1207, 2000. 